ISSN $0717-2877$

Universidad de Talca - Facultad de Ciencias Jurídicas y Sociales

La prohibición de decisiones-sorpresas: reinterpretación del iura novit curia desde el debido contradictorio

Álvaro Pérez Ragone

Trabajo recibido el 17 de junio de 2019 y aprobado el 06 de octubre de 2019

\title{
La prohibición de decisiones-sorpresas: reinterpretación del iura novit curia desde el debido contradictorio
}

\author{
THE PROHIBITION OF SURPRISE-JUDGEMENTS: REINTERPRETATION OF IURA NOVIT CURIA FROM THE DUE \\ CONTRADICTORY
}

Álvaro Pérez Ragone*

\begin{abstract}
RESUMEN
El principio de que el juez conoce el derecho y puede decidir la calificación jurídica y finalmente la norma aplicable al caso (iura novit curia) en forma autónoma y en un soliloquio es reemplazada por la necesidad del diálogo previo con las partes sobre la posibilidad de considerar una visión del derecho aplicable que aquellas no tuvieron en cuenta. Hablamos así de un iura novit curia dialógico, de modo tal que la decisión del juez no sorprenda a las partes y además haciendo a estas partícipes de cómo se decidirá el caso Aquellas decisiones que sorprenden en su contenido - ya lista y pronunciada la sentencia - a las partes y que bien pudieran haberse discutido con antelación son el centro de atención. Debe brindarse oportunidad a las partes para ser oídas respecto a un iura novit curia pensado con y en el contradictorio. Este estudio demuestra la correlación entre el deber de colaboración vinculado con el iura novit curia que posibilitan un adecuado contradictorio con una discusión trilógica de los involucrados en el proceso civil para una decisión más justa. Se utiliza la metodología dogmático-comparada para llegar a las conclusiones que defienden estas posturas a partir de la hipótesis enunciada.
\end{abstract}

\section{ABSTRACT}

The principle that the judge knows the law and can decide the legal classification and finally the rule applicable to the case (iura novit curia) autonomously and in a soliloquy is discussed. There is the need for prior dialogue with the parties about the possibility of considering a vision of the applicable law that did not was considered previously. We speak thus of a dialogical iura novit curia, in such a way that the decision of the judge does not surprise the parties and also making these participants of how the case will be decided. Those decisions that surprise in their content -already ready and pronounced the judgement - to the parties and which could well have been discussed in advance are the focus of attention. The parties must be allowed to be heard regarding the iura novit curia. This study demonstrates the correlation between the duty of collaboration linked to the iura novit curia that allows an adequate contradiction with a plural discussion of those involved in the civil process for a fairer judgement. The dogmatic-comparative methodology is used to arrive at the conclusions that defend these positions from the stated hypothesis.

PALABRAS CLAVE

Cooperación, Contradictorio, lura novit curia, decisiones sorpresivas.

KEY WORDS

Cooperation, Discussion, Iura Novit Curia, Surprise-judgment.

\footnotetext{
* Profesor e investigador externo (Universidad Católica del Norte, Antofagasta, Chile). Profesor Titular de Derecho Procesal Civil Univeesidad San Pablo-Tucumán. Av. Estado de Israel 1062, CP. 4000, Tucumán, Argentina. Tel: 543814345033. Cel: 5493814180660. Email: alvaro.perez01@ucn.cl.
} 


\section{Introducción}

El presente trabajo pretende abordar el tema de las decisiones sorpresa, teniendo en cuenta las posiciones perfiladas por la doctrina y la jurisprudencia comparada. El principio de la cooperación se vuelve imprescindible para el entendimiento de la materia, teniendo en cuenta ser considerado el nuevo vector del derecho procesal civil contemporáneo, acarreando un cambio de perspectiva del formalismo del proceso, que pasa a demandar una actividad comparticipada de los sujetos procesales $^{1}$.

El contradictorio efectivo pasa entonces a desempeñar un papel esencial en el proceso, ya que es responsable de permitir el ejercicio del poder de influencia de las partes sobre la formación del conocimiento judicial para la decisión por el debate sobre de las cuestiones, de hecho y de derecho que se ventilen ${ }^{2} . Y$, esta especie de decisión se considera indeseable a los ordenamientos procesales contemporáneos, por lo que su vedación es prescrita, aunque implícitamente, por ellos, siendo igualmente previstos remedios procesales para su impugnación en el proceso ${ }^{3}$.

Todo ello, por entender que tales informaciones son esenciales para la mejor comprensión de esta estructura cooperativa del proceso, en que la distribución de los papeles entre los sujetos procesales es hecha de forma innovadora, lo que atraviesa por la concientización de la importancia del deber de gestión / dirección (gerenciamiento) que se atribuye al magistrado (case management), una vez que en él se inserta los deberes de cooperación, especialmente, el deber de consulta, imprescindible para el análisis de la temática principal, la cuestión de las decisiones sorpresa ${ }^{4}$.

El principio de que el juez conoce el derecho y puede decidir la calificación jurídica y finalmente la norma aplicable al caso (iura novit curia) en forma autónoma y en un soliloquio es reemplazada por la necesidad del diálogo previo con las partes sobre la posibilidad de considerar una visión del derecho aplicable que aquellas no tuvieron en cuenta. Hablamos así de un iura novit curia dialógico, de modo tal que la decisión del juez no sorprenda a las partes y además haciendo a estas partícipes de cómo se decidirá el caso 5 . Aquellas decisiones que sorprenden en su contenido - ya lista y pronunciada la sentencia - a las partes y que bien pudieran haberse discutido con antelación son el centro de atención ${ }^{6}$. Debe brindarse oportunidad a las partes para ser oídas respecto a un iura novit curia pensado con y en el contradictorio': ¿Qué sucede si el tribunal luego del estudio del caso y/o durante la audiencia de vista de la causa en base a aquel principio piensa en una nueva hipótesis jurídica de solución de la causa? Hasta ahora en muchos ordenamientos donde la influencia germana no es relevante era incuestionable que ello puede y debe hacerlo de oficio, conoce él el derecho aplicable, la objeción es que de ello recién toman conocimiento las partes cuando esté la sentencia a disposición, y por ello son calificables de sorpresivas para las partes ${ }^{8}$.

Esta investigación se compone de las siguientes partes, en primer lugar se propone una visión renovada del tradicional iura novit curia (II); se trata luego de la cooperación procesal y sus

\footnotetext{
${ }^{1}$ FRITSCHE (2016), pp. 1-10; CADIET et al. (2010), p. 385.

${ }^{2}$ CADIET (2010), pp. 635-655.

${ }^{3}$ GOMILLE (2016), p. 412.

${ }^{4}$ KETTEMBEIL (1978), pp. 10-25; ZUFELATO (2019), pp. 49-52.

${ }^{5}$ WIEGAND (2005), p. 127.

${ }^{6}$ TARZIA (1981), p. 789

${ }^{7}$ Sobre el iura novit curia y el contradictorio puede verse MEROI (2006).

${ }^{8}$ Comp. la visión tradicional de los alcances del iura novit curia en EZQUIAGA (2000), p. 18. Sumando a este problema la necesidad del contradictorio puede verse PICARDI (2003a), pp. 7-22; COMOGLIO (1989), p. 26
} 
incidencias en el tema (III) Sigue con ejemplos del derecho comparado alemán, portugués, austríaco y brasileño que incorporaron en los últimos años disposiciones específicas en relación al tema (IV). A continuación se desarrollan las relaciones entre el deber de cooperación y la prohibición de decisiones sorpresas a lo que se suma luego (V) y presentar las conclusiones (VII).

\section{Visión renovada del iura novit curia}

El juez debe conocer el Derecho. Casi parece que el mismo concepto de iura novit curia está condensado en estas tres palabras por la sintaxis simple e invertida y por el sonido cautivador, por lo que a menudo se acompaña otro aforismo, iura novit curia e da mihi factum, dabo tibi ius ${ }^{9}$. Este segundo no expresa una afirmación asertiva, sino que se plantea desde una perspectiva dialéctica, de hecho, las proposiciones dialógicas: que de manera inmediata y definitiva transmiten el significado ineludible y perentorio de la supremacía del poder judicial sobre la regulación jurídica de los conflictos sociales ${ }^{10}$.

Sin embargo, el problema del conocimiento del texto normativo es solo una manifestación particular de otro problema más general: el principio iura novit curia expresa la solución al problema de la calificación y subsunción legal de los hechos y la demanda, en particular establece el deber del juez de la actuación del derecho para el caso concreto ${ }^{11}$. Impone la correspondencia entre lo solicitado y lo decidido partiendo de que: (i) no siempre las partes alegarán la norma jurídica correcta para el caso; (ii) o que aún alegándola, en un sentido, podría haber interpretaciones jurisprudenciales y doctrinales en otro ${ }^{12}$. De allí que no solo para las cuestiones fácticas el contradictorio haya asumido un rol relevante en el proceso valorativo y participativo, sino también para las cuestiones de derecho ${ }^{13}$.

La importancia del justo proceso impone que también el iura novit curia pueda ser dialogado y retoma importancia el contradictorio. Así con corrección se sostiene que la tutela efectiva de los derechos no se supedite solo a la astucia o habilidad mayor o menor del justiciable para escoger en base al principio dispositivo la correcta norma aplicable, lo que ya por sí es un desafío elevado ${ }^{14}$. El paradigma cambia y la calificación como fundamentación precisan del contradictorio también en lo relativo al derecho aplicable ${ }^{15}$.

El diálogo procesal, impone una activa participación del juez y la igualdad de armas de las partes, esta vez con relación al derecho que finalmente resultará aplicable al caso ${ }^{16}$. Los abogados desempeñan acá un rol preponderante en la correcta adecuación jurídica de las pretensiones y defensas de las partes, pero ello no exime de que en definitiva conociendo el juez el derecho pueda desviarse de los fundamentos propuestos ${ }^{17}$. Sucede que ello no puede ser unilateral, sino que precisará del previo contradictorio de las partes, visto este ya no como simple derecho de bilateralidad, sino como derecho a influir activamente en la decisión a tomarse ${ }^{18}$.

\footnotetext{
${ }^{9}$ SENTÍS (1957), p. 14.

${ }^{10}$ ORMÁZABAL (2007), pp. 5-20.

${ }^{11}$ KETTEMBEIL (1978), pp. 5-20.

12 SPRUNG Y KÖNIG (1985), p. 237; PROTO (2010), p. 301; PRÜTTING (2016b), pp. 2-6.

${ }^{13}$ HUNTER (2010), pp. 201-216.

${ }^{14}$ HUNTER (2013), pp. 601-640.

${ }^{15}$ CAPONI (2001), p. 282.

${ }^{16}$ CHIARLONI (1987), pp. 575-580.

${ }^{17}$ PICARDI (2003a), pp. 7-22; COMOGLIO (1989), p. 26

${ }^{18}$ PICARDI (2003b), p. 53; WIEGAND (2005), p. 127.
} 


\section{Cooperación procesal y correcta decisión del caso}

La necesidad de una justicia civil, procesos, jueces, y partes intervinientes creíbles y leales, aún cuando el postulado parezca una utopía, tal cual como se pretende desarrollar acá podría ser una alternativa válida. Los componentes básicos para poder hablar de una "buena justicia civil" se podría reducir a cuatro: en primer lugar el acceso a la justicia y a los tribunales, traducido en la eliminación de vallas de carácter económico y socio-cultural que otros de a la buena prestación y asignación del recurso justicia, como así también la minimización de información tergiversada entre el juez y las partes; un segundo componente consiste en que el acceso y posterior salida de la prestación debe realizarse con criterios de eficacia y eficiencia, ya que justicia tardía no es justicia; un tercer componente exige que la serie de procedimientos, y las relaciones del tribunal para con las partes y terceros se ve respetando la dignidad de cada uno, lo que vamos a terminar requisito de proceso equitativo, justo y debido; finalmente como último componente se debe mencionar que el producto o resultado obtenido de la prestación del servicio de justicia debe ser legítimo, creíble y convincente ${ }^{19}$.

Estos cuatro componentes debieran contribuir, siempre que se respeten, a que la tutela de los derechos y la solución de controversias se pueda desenvolver de tal manera que cualquiera sea el resultado (adverso o favorable) para una parte en concreto, es siempre respetable, es decir legítimo ${ }^{20}$. Uno de los principales inconvenientes, no solamente doctrinarios sino también de técnica legislativa, y hasta incluso de visión político-procesal fue discutir durante los siglos XIX, XX y XXI cuál es el rol asignable a partes, terceros $y$ al juez en un proceso civil ${ }^{21}$. Si se consideraba que necesariamente las partes que intervienen en pie de igualdad con conocimiento de la información favorable o no propia y ajena relacionada con su caso, sería posible exigirle al juez una actitud absolutamente pasiva, que finalmente asumirá un rol de jerarquía solo el momento del pronunciamiento de la sentencia. Pero esta hipótesis de igualdad de las partes o intervinientes en un proceso civil, en consideración solo una igualdad de carácter formal ${ }^{22}$. Ello aún cuando desde el punto de vista axiológico o de la justicia sea posible incluir que la parte perdió no porque no le asistía la razón sino porque las reglas y dominio del juego que implica el proceso eran mucho mejor manejadas por la contraparte ${ }^{23}$. Los llamados principios o máximas formativas del proceso permanecieron mucho tiempo sin ser debidamente reflexionadas teniendo una vigencia en tanto axiomas sin poder ser reconsiderados ${ }^{24}$. Muchos de ellos se traducían en principios, normalmente inoperables, y meramente descriptivos para diferenciar los distintos sistemas de justicia civil ${ }^{25}$.

Así la discusión en torno a lo teórico sin ninguna finalidad pragmática, dejaba de lado considerar en concreto cuál era el rol asignar a las partes, al tribunal y a los terceros. La mayor o menor duración de un proceso en concreto, la mayor o menor legitimidad de su sentencia por la peor o mejor calidad argumentativa que comprende la consideración de la prueba, no es por sí solo una cuestión que debiera interesar a las partes, sino también a todo el conjunto de ciudadanos que con sus tributos financian al sistema de administración de justicia ${ }^{26}$.

\footnotetext{
${ }^{19}$ CABRAL (2005), p. 450; OLIVEIRA (2003), pp. 62-67.

${ }^{20}$ DIDIER JR. (2010a), p. 18.

${ }^{21}$ Ver ya la visión social del derecho en WASSERMANN (1978), pp. 97-120.

${ }^{22}$ Ver las críticas a estas visiones por KLEIN (1891), pp. 1-20; Ver KOCHEM (2016), pp. 75-111.

${ }^{23}$ MEIER (2014), pp. 35-67; STICKELBROCK (2002), pp. 595-597.

${ }^{24}$ SPOHR (1969), pp. 10-35; BAUR (1968), pp. 75-82.

${ }^{25}$ RIMMELSPACHER (1966), pp. 23 y ss.; KLEIN (1927), p. 190.

${ }^{26} \mathrm{KOCH}$ (2013), pp. 102-103; THEODORO JR. (2011), p. 64.
} 
La necesidad de un "fair play" procesal impone no solo colaborar, sino además hacerlo de manera leal ${ }^{27}$. El principio de aporte de parte, de quienes tienen interés en el proceso como demandante o demandado, de terceros se veía también nublado por el principio nemo contra se edere tenetur que de alguna manera marcaba el límite del imperativo que recaía sobre cada uno de los sujetos en relación a la información que podía, debía o le convenía aportar al proceso. Este principio justamente se fundaba en que la justicia civil era "cosa o materia de interés particular", por ende estratégicamente maneable, dilatable y al ser un juego debía ganar el más astuto ${ }^{28}$.

De ninguna manera el juez sustituye en esta visión a las partes quienes pueden disponer sobre el objeto del proceso y el juez solamente puede usar aquello que las partes decidan integre determinado proceso así en la relación entre el derecho procesal y la concepción de derecho sustantivo lo que se corresponde con la posibilidad de disponer sobre el material o elemento litigioso y su relación entre el derecho procesal por un lado y el derecho constitucional por otro. Esta doble posibilidad, traducida en un derecho que titularizan las partes procesales, se manifiesta en solicitar a la jurisdicción o accionar como así también de defenderse por un lado. Por otro con la posibilidad de influenciar en la tramitación y el contenido del proceso, determinando lo que se peticiona y en base a qué hechos y en su caso hasta la invocación del derecho que va servir de fundamentación para lo peticionado se manifiesta a través del principio dispositivo en el aporte probatorio a instancia de las partes ${ }^{29}$. En efecto las partes deciden el inicio la extensión o ámbito de discusión y conocimiento en el proceso, o eventual modificación, prosecución, e incluso la posibilidad de extinción del proceso sin que medie una actividad o decisión por parte del juez ${ }^{30}$.

El desarrollo jurídico en la historia del derecho procesal civil ha conducido desde fines del siglo XIX hasta finales del siglo XX, con las últimas grandes reformas europeas, latinoamericanas y asiáticas, a un aumento del poder del juez ${ }^{31}$. Así consecuentemente de su responsabilidad en la dirección y manejo del proceso que dio como resultado pasar de un simple juez conocedor a un juez director y organizador (juez activo) ${ }^{32}$. Veremos de qué manera se aplican a aquello y entre quienes se discute en un proceso civil. De qué forma es posible sostener que el juego limpio en un proceso civil exige veracidad, cooperación para el esclarecimiento o información. La relación cooperativa se da de las partes para con el juez, pero también del juez para con las partes ${ }^{33}$.

\section{Ejemplos de modelos cooperativos y con valoración del contradictorio para evitar decisiones- sorpresas}

Veamos cómo se regulan en modelos con reformas recientes estos postulados, se toman como ejemplo el alemán, luego el portugués, el brasileño y el austríaco.

\footnotetext{
${ }^{27}$ BOURSIER (2003), pp. 290-300.

${ }^{28}$ VENTSCH (2005), pp. 40-53; RASSI (2013), p. 767; KAUFMANN-KOHLER (2004), p. 71; KOCH (2003), pp. 120-135; BALLON (1995), p. 623; SCHARWITZL (2013), pp. 139-141.

${ }^{29}$ GUASTINI (2004), pp. 123-140.

${ }^{30}$ KUGLER (2002), pp. 200-230; AGUIRREZABAL Y PÉREZ (2018), pp. 72-75.

${ }^{31}$ Ver la visión tradicional de los alcances del iura novit curia en EZQUIAGA (2000), p. 18; Por otra parte, PICARDI (2003a), pp. 7-22; COMOGLIO (1989), p. 26.

${ }^{32}$ SCHÖPFLIN (1992), pp. 17-26; BAUR (1968), pp. 76 y ss.; PRÜTTING (1980), p. 361.

${ }^{33}$ GREGER (2000a), pp. 73-84.
} 


\subsection{Modelo alemán}

Un objetivo de la reforma alemana del año 2002 fue fortalecer la primera instancia y de esta forma lograr cierta celeridad. En el proceso en su momento se dijo "el juez debe esclarecer, tratar forma completa los hechos y el derecho en el proceso" (traducción libre) ${ }^{34}$. Como antecedente en la discusión dogmática alemana ya en septiembre del año 2000 en el marco del Congreso alemán de juristas número 63 comenzó a considerarse como objeto de la reforma la ampliación de los deberes de esclarecimiento de las partes. No hay posibilidad de arribar a una decisión fundada sin que el juez cuente con un convencimiento sobre las razones alegadas por cada una de las partes, y ese convencimiento lo consiguen las partes como finalidad para poder obtener una resolución favorable ${ }^{35}$.

El juez y las partes son las figuras centrales del proceso civil alemán. De allí que sea necesario previamente aclarar los alcances de la distinción doctrinaria entre principio dispositivo y de oficialidad, y por otro, en cuanto a la iniciativa y actividad probatoria, entre principio de aportación de parte y principio inquisitivo. Un principio fundamental es el del control de las partes del inicio, mutación, fin y objeto del proceso (principio dispositivo). El juez es responsable (oficialidad), en el proceso alemán, de que las partes decidan correctamente respecto de los hechos discutidos y las cuestiones de derecho en relación con sus alegaciones ${ }^{36}$. Para ello el ZPO brinda las herramientas de actuación oficiosa del tribunal y las reglas de cargas y deberes en las relaciones de partes y terceros. Así, el proceso civil está completamente dominado por las partes. Son las partes y sus abogados quienes determinan el objeto del juicio a través de sus actos de postulación (principio dispositivo) y quienes incorporan los hechos y los medios de prueba (principio de controversia).

El § 139 del ZPO fue y es considerado en el proceso civil alemán, como uno de los pilares del proceso justo ${ }^{37}$. Este parágrafo regula el impulso y dinámica procesal en general, tanto en su redacción actual como antes de la reforma del 2002. No estaba contenido en el proyecto de Código Procesal Civil publicado en 1871 y, recién con el Código y la renumeración de la reforma de 1898, fue estructurado en tres apartados ${ }^{38}$. En los hechos, las reformas realizadas hasta el 2002 no resultaron exitosas. La praxis fue reticente a la aplicación plena del parágrafo mencionado, sencillamente porque las aclaraciones y preguntas que puede hacer el tribunal no eran valoradas con suficiencia ya que, para el juez y para las partes, lo ideal es la tramitación con celeridad y el arribo a una sentencia definitiva sin mayores trabas. Por tres motivos este parágrafo no tuvo éxito en la praxis. En primer lugar, las audiencias eran tardíamente preparadas; incluso el presidente recibía los expedientes, así como los dictámenes pertinentes, con una semana o días de anticipación a la audiencia oral. En caso de creer pertinentes determinadas aclaraciones, obviamente surgía el temor de que fueran introducidas nuevas cuestiones de hecho o de derecho que podrían tácticamente obstaculizar el dictado inmediato de una sentencia y llevar a que debieran ser resueltos en posteriores audiencias. También colaboró con ello el Supremo Tribunal Federal Alemán con decisiones, en las cuales se expresaba que la parte con representación letrada no tenía derecho a avisos o instrucciones del juez que tuvieran que ver con la sustentación o aplicación del derecho material o una cuestión fáctica determinada. Más aún, en el año 1990 el BGH volvió sobre sus pasos,

\footnotetext{
${ }^{34}$ En relación al proyecto de reforma por entonces GREGER (2000b), pp. 842 y ss.; HANSENS (2002), pp. 125-126; SCHELLHAMMER (2001), pp. 1081, 1082 y ss.

${ }^{35}$ STÜRNER (1976), pp. 10-60.

${ }^{36}$ STÜRNER (1982), pp. 15-25.

${ }^{37}$ STÜRNER (1982), pp. 1-15; RENSEN (2002), pp. 1-15.

${ }^{38}$ SCHNEIDER (2002), pp. 55-60.
} 
contrariando la precedente jurisprudencia a favor de la potestad esclarecedora del juez ${ }^{39}$. De modo tal, la poca claridad sobre los alcances y la aplicación de estas disposiciones ofrecía reparos no solo en la práctica, sino que además fue reiteradamente cuestionada por la jurisprudencia ${ }^{40}$.

Con la reforma del 2002, en el § 139 ZPO se introducen por un lado el apartado 3 del antiguo $\S 278$ ZPO, acoplándola a la redacción actual del § 139. En su actual redacción, el § 139 ZPO se divide en cinco apartados. El primero establece que el tribunal puede aclarar con las partes las cuestiones de hecho contradictorias realizando las preguntas pertinentes. De este modo el tribunal colabora e incentiva a las partes para lograr una completa manifestación y en tiempo sobre las cuestiones de hecho relevantes. El apartado 2 establece que cuando un punto de vista no haya sido reconocido por una parte o haya sido considerado como irrelevante por ambas, el tribunal podrá fundamentar su decisión solamente cuando hubo oportunidad para manifestarse y discutir con aquellas sobre ello y siempre que se circunscriba a algo meramente accesorio. Ello también es válido cuando el punto de vista del tribunal sea absolutamente contrario al de las partes. El apartado 3 del parágrafo establece el derecho del tribunal de llamar la atención en las cuestiones atinentes al ejercicio de poderes de oficio. El apartado 4 establece que el tribunal puede y debe realizar las aclaraciones atinentes para el conocimiento del expediente para prevenir errores y poder dar oportunidad a las partes del conocimiento de aquel en su totalidad y en las copias que se soliciten. En el apartado 5 se establece que si una parte no puede realizar las aclaraciones pertinentes solicitadas por el tribunal, este puede fijar un plazo - a solicitud de las partes - para que la parte presente la aclaración por escrito ${ }^{41}$.

El § 139 ZPO debe ser analizado desde dos puntos de vista: por un lado, el contenido en su aplicación, es decir, el cúmulo de deberes (y facultades) que contempla y, en segundo lugar, los efectos de la violación de estos deberes. De la combinación de los deberes que se describen a continuación, en especial del de discusión la doctrina y jurisprudencia sustentan la prohibición de decisiones sorpresas, justamente por instar al diálogo en los hechos y el derecho ${ }^{42}$.

\subsubsection{Deber de discusión}

El § 139 ZPO obliga al tribunal, en colaboración con las partes, al esclarecimiento de aquello que se discute y debe ser decidido en el proceso. Este deber pesa en la cabeza del juez y tiene por objetivo que todos los involucrados puedan precisar aquello sobre lo que se discute, los alcances, sus coincidencias, diferencias y qué solicitan concretamente. Sí se exige del tribunal una prudencia en el ejercicio de este deber de esclarecimiento, de modo que pueda brindar igual oportunidad a las partes para ser oídas (como componente del proceso debido y justo) ${ }^{43}$. En relación con ello hay que recordar que el Tribunal Constitucional Federal (BVerfGE) se pronunció claramente en favor de la tutela del derecho a ser oído y del derecho de defensa sobre la base de esta disposición en su aplicación extralimitada ${ }^{44}$. El deber de discusión comprende tanto las cuestiones de hecho como de derecho. Estas últimas especialmente no deben quedar por ser materia jurídica solo elegibles y aplicables de oficio por el tribunal, sino que deben siempre previamente sujetarse al contradictorio

\footnotetext{
${ }^{39}$ Véase al respecto el comentario de FRITSCHE (2016).

40 Supremo Tribunal Federal Alemán BGH, de 1984, p. 310.

${ }^{41}$ REISCHL (2003), pp. 81-102; compárese SCHAEFER (2002), p. 849.

42 SMID (2013), p. 218; FRITZ (1979), pp. 20-35 (referido a la antigua redacción anterior a la reforma del 2002 que acopló el §278 III al $\S 139)$.

${ }^{43}$ FRITSCHE (2016), pp. 9-18.

${ }^{44}$ Decisión del Tribunal Federal Constitucional BVerGE, de 1984, p. 190.
} 
de las partes ${ }^{45}$. Una decisión aplicando un precepto jurídico que no fue objeto de discusión es objetable.

\subsubsection{Deber de instrucción y de interrogación}

Siempre que surjan dudas sobre aquello que sirve de fundamento a las partes, sean hechos sea el derecho que invocan, el tribunal debe preguntar a las partes. Las preguntas pueden ser realizadas aun en forma de indicaciones. El mismo Tribunal Constitucional Federal considera contrario a la Ley Fundamental que el deber de interrogación o indicación no sea ejercido en el supuesto de una decisión jurisdiccional. Así es, por ejemplo, en caso de argumentaciones o consideraciones que no sean sostenibles y en las que el tribunal debe ejercer su deber de pregunta e información. Ello fue considerado por el Tribunal Constitucional Federal como contrario al artículo 3, apartado 1 ㅇ de la Ley Fundamental ${ }^{46}$.

\subsubsection{Deber de esclarecimiento y función saneadora}

El punto de partida esencial del § 139 ZPO es la clara y transparente fundamentación de una decisión judicial. Ello debe resultar apreciable tanto para las partes como para el tribunal, de manera clara e indiscutida, el porqué y el cómo de una decisión. El BGH alemán se pronunció al respecto en el sentido de que las contradicciones en cuestiones relevantes de la demanda deben ser esclarecidas antes de que pueda arribarse a la fundamentación de una sentencia ${ }^{47}$. Para ser coherentes con el deber de indicación, y en combinación con el deber de discusión y esclarecimiento, el tribunal puede discutir con las partes a los efectos de esclarecer las peticiones o solicitudes de ellas. El límite está dado en que el juez no debe ejercer los deberes y facultades antes mencionados de una manera arbitraria que conduzca a perjudicar la posición de una de las partes ${ }^{48}$.

De acuerdo con el $\S 139$ apartado 3 ZPO, el tribunal igualmente debe realizar las advertencias, indicaciones y requerimientos de las aclaraciones pertinentes de las partes, en todo lo que se corresponda con actos realizables de oficio ${ }^{49}$, sea en cuestiones de derecho o de hecho. Como contrapeso, en el caso de que el tribunal efectivice la introducción de pruebas de oficio, las partes tienen derecho a ser oídas y a manifestarse al respecto, de acuerdo con la decisión del Superior Tribunal Constitucional de $1910^{50}$.

\subsubsection{Deberes de documentación y registro del proceso}

El agregado del apartado cuarto al § 139 ZPO es importante en tanto y en cuanto el tribunal debe cumplir con todas las obligaciones pertinentes a la debida documentación y protocolización de los actos procesales, y a los deberes pertinentes de publicidad de los actos documentales y de protocolización o registro dentro del proceso. Las indicaciones, aclaraciones y advertencias que realice el juez deben ser debidamente protocolizadas o tomadas en el expediente de la manera

\footnotetext{
45 LÖCHER (2005), pp. 40-43.

${ }^{46}$ En decisión del Tribunal Federal Constitucional alemán BVerfGE, en NJW, de 1976, 1391 (ya antes de la reforma 2002).

${ }^{47}$ En decisión del Supremo Tribunal Federal alemán BGH, en MDR, de 2001, 104 (ya antes de la reforma 2002)

48 BÜNNIGMANN (2013), pp. 21-22.

${ }^{49}$ FRITSCHE (2016), pp. 49-51.

50 Según lo decidido por Tribunal Constitucional Federal alemán BVerfGE 10, p. 182; BVerfGE 15, 218.
} 
adecuada para ello; de esta manera, el ejercicio de los deberes del presente parágrafo es registrados en el expediente y solamente pueden ser impugnados por demanda de falsedad ${ }^{51}$.

\subsubsection{Emplazamiento para manifestarse y conclusión de las audiencias}

La apartado quinto del § 139 ZPO regula el deber del tribunal de conceder un plazo a las partes a los efectos de que estas se manifiesten cuando puedan hacerlo, habiendo el tribunal realizado una pregunta referida a aclaraciones o manifestaciones al respecto de una manera adecuada y oportuna en el tiempo ${ }^{52}$. El derecho que tiene una parte al otorgamiento de un plazo para manifestarse sobre un requerimiento específico, no implica el correlativo derecho de la otra para aclarar, integrar o refutar sobre lo que de manera escrita la parte haya manifestado en ese plazo. EI § 156 ZPO determina que, aun cuando una audiencia ya haya sido clausurada, bajo determinadas condiciones se permite la inclusión de nuevos elementos que permitan que la audiencia pueda reabrirse para que las partes se manifiesten ${ }^{53}$.

La sincronía de estos deberes de colaboración del tribunal para con las partes y de estas para con el tribunal se dan también en el plano del derecho aplicable al objeto del proceso determinado por el diálogo entre los intervinientes. Un diálogo que impide la sentencia o decisión sorpresa por el tribunal. En otras palabras el tribunal debe previamente dialogar con las partes, en su caso indicar la calificación jurídica que de acuerdo a lo demarcado como objeto del proceso podría ser la aplicable, sin que ello implique prejuzgamiento. El Supremo Tribunal Federal alemán calificó a este tipo de decisiones sin el contradictorio sobre el derecho como aquellas que no son útiles a nadie. El artículo 103.1 de la Ley fundamental otorga al individuo el derecho a hablar antes de una decisión sobre sus derechos para poder influir en el procedimiento y su resultado ${ }^{54}$.

\subsection{Otros modelos: Portugal, Brasil y Austria}

En el caso del modelo portugués es influenciado por la visión alemana antes descrita en tanto el texto del artículo $266^{55}$. En estas coincidencias de modelos no se puede obviar, igualmente, de la finalidad política del proceso, que puede ser descrita por la promoción efectiva de tres valores estatales y democráticos fundamentales: poder, libertad y participación. La afirmación del poder estatal, primer ámbito político del proceso, es conquistada por el ejercicio reiterado de la jurisdicción, una vez que, intermediadas por el proceso, las decisiones estatales son fijadas e impuestas imperativamente, siendo posteriormente inmunizadas por la cosa juzgada, así, definitivas. El segundo objetivo político de la jurisdicción es el culto a las libertades públicas, principalmente, cuando corresponde a la relación entre individuo y Estado, comprometiéndose este a observarlas y a limitar el ejercicio de su poder, de modo a no invadir el espacio de libertad especialmente cuando no hay daño al grupo o al desarrollo de los objetivos comunes de la sociedad. El último ámbito político se configura en la canalización de la participación democrática por la

\footnotetext{
51 PRÜTTING (2016a).

${ }^{52}$ Lo decidido por el tribunal supremo de Colonia OLG Colonia, en NJW-RR, de 1987, 1152.

${ }^{53}$ FRITSCHE (2016), pp. 1-13.

${ }^{54}$ Así el Tribunal Federal Constitucional Alemán BVerfGE 51, p. 192; 75, p. 190; y el Supremo Tribunal Federal BGH vom de 29.04.2014.

${ }^{55}$ El artículo enuncia: "1. Na condução e intervenção no processo, devem os magistrados, os mandatários judiciais e as próprias partes cooperar entre si, concorrendo para se obter, com brevidade e eficácia, a justa composição do litígio. 2. O juiz pode, em qualquer altura do processo, ouvir as partes, seus representantes ou mandatários judiciais, convidando - os a fornecer os esclarecimentos sobre a matéria de facto ou de direito que se afigurem pertinentes e dando- se conhecimento à outra parte dos resultados da diligência".
} 
posibilidad de influencia en los centros de poder, representando peso en la toma de las decisiones del Estado ${ }^{56}$.

La idea de instrumentalidad presenta el proceso como un "sistema concebido para la realización del orden jurídico, incluso la constitucional, revelando así dos sentidos vectoriales en la relación entre aquel y la constitución" ${ }^{15}$. Pero ello resulta insuficiente sin la visión valorativa del proceso. El sentido proceso-constitución, consubstanciado en el control de constitucionalidad de las leyes y actos administrativos, así como la preservación de las garantías constitucionales a través de una jurisdicción constitucional ${ }^{58}$. En el sistema portugués, la prohibición de la sorpresiva decisión fue originalmente introducido por el Decreto Legislativo no 329-A / 95, que en su preámbulo se califica como una dimensión de la contradictoria. La versión, actualmente en vigor, del texto normativo responsable de su previsión es, sin embargo, resultado de la modificación operada por el Decreto-ley no 180/1996, que sustituyó el término "actuando con la diligencia debida" -dirigida a las partes con el propósito de evitar que vinieran a las mismas a beneficiarse de su propia negligencia- por la expresión "salvo caso de manifiesta innecesaria" - dirigida al magistrado-. Si el dispositivo está contenido en el art. 3ํ, no 3 -recepcionado íntegramente por el Novo Codigo de Processo Civil (NCPC) - con la siguiente redacción:

Artículo 3 - Necesidad de la solicitud y de la contradicción(...)

3. El juez debe observar y hacer cumplir, a lo largo de todo el proceso, el principio del contradictorio, no siendo lícito, salvo en caso de manifiesto innecesaria, decidir cuestiones de derecho o de hecho, aunque de conocimiento oficioso, sin que las partes hayan tenido la posibilidad de pronunciarse sobre ellas $(\ldots)^{59}$.

Parte de la doctrina, sin embargo, suele tratar las decisiones sorpresa como un acto inválido en razón del incumplimiento del principio del contradictorio, y no del principio de la cooperación ${ }^{60}$.

Se puede decir, de esta forma, que el instrumentalismo fue una fase eminentemente crítica, en que el proceso dejó de ser percibido como mera técnica formal, asumiendo la estructura de un verdadero instrumento ético, impregnado por valores constitucionales, para la persecución de ámbitos no solo jurídicos, como también políticos y sociales, rompiendo con la visión del proceso estrictamente por el ángulo interno. Se pasa a comprender que el proceso es más que mero instrumento técnico, pero un instrumento ético destinado a servir a la sociedad y al Estado, posibilitando el acceso a la justicia ${ }^{61}$. El neoprocesalismo - Formalismo-Valorativo brasileño de Carlos Alberto Álvaro de Oliveira, con la intención de destacar la importancia de la buena fe procesal como aspecto ético del proceso-, se desarrolla en Brasil como una cuarta fase metodológica del derecho procesal civil. Sin dejar de lado las conquistas del procesalismo y del instrumentalismo, presenta un nuevo repertorio teórico, reflejándose en la revisión de las categorías procesales existentes a partir de nuevas premisas teóricas ${ }^{62}$. Así en Brasil el modelo cooperativo impone per se la prohibición de decisiones sorpresas ${ }^{63}$. Ello es cooperación para lograr una decisión adecuada en un plazo razonable que sea justa y efectiva como reza el actual art. 6 del Código de Processo Civil

\footnotetext{
${ }^{56}$ DINAMARCO (2008), pp. 188-189.

${ }^{57}$ Puede verse al respecto la obra de DIDIER (2010a), pp. 23-40.

${ }^{58}$ MITIDIERO (2009), p. 34.

${ }^{59}$ TORRES (2014), pp. 95-96; FREITAS (2013), p. 125.

${ }^{60}$ MITIDIERO (2009), pp. 121-122.

${ }^{61}$ MITIDIERO (2004), pp. 487-488.

62 OLIVEIRA (2006), p. 66.

${ }^{63}$ MEDEIROS Y OLIVEIRA (2016), pp. 163-191.
} 
del Brasil ${ }^{64}$. Tanto las sentencias como las sentencias (y decisiones interlocutórias, en el caso del derecho brasileño) pueden ser configuradas como decisiones sorpresa ${ }^{65}$.

El nuevo Código de Processo Civil del Brasil establece como consecuencia de la necesidad del contradictorio el deber del juez de indicar las calificaciones jurídicas (art. 357.IV) y no es casual que sea luego de las resoluciones relativas al saneamiento y organización del proceso. Ello se debe a que el juez no debe sorprender a las partes con calificaciones o decisiones que no fueron objeto de contradictorio por las partes. Ello implica que si el tribunal tuviere otra visión jurídica de las probables normas jurídicas a aplicar en el proceso, diferente a las tesis de las partes, debe previamente permitir que estas la conozcan primero y se genere un contradictorio sobre las mismas. Incluso sostiene la doctrina, con razón, que la cooperación procesal juez-partes, se ve desplazada por el principio prevalente de la necesidad del debido contradictorio con fundamento en el artículo 10 del Código que termina siendo la regla madre e impregnando al art. 357 íntegramente ${ }^{66}$.

Art. 10. O juiz não pode decidir, em grau algum de jurisdição, com base em fundamento a respeito do qual não se tenha dado às partes oportunidade de se manifestar, ainda que se trate de matéria sobre a qual deva decidir de ofício.

En la defensa del protagonismo judicial procesal y de la visión publicista del proceso como un medio para la realización de la justa y rápida composición del litigio, conviene aclarar que no hay ninguna correlación directa y absoluta entre regímenes autoritarios / totalitarios y aumento de los poderes judiciales ${ }^{67}$. El diseño balanceado entre los poderes-deberes del juez y las garantías a las partes, tales como, contradictorio, disposición e igualdad, serían la clave para apartar el autoritarismo judicial y permitir la presencia de un juez activo en el proceso ${ }^{68}$. Por lo tanto, la atribución de poderes al magistrado acarrearía directamente la disminución de poderes de las partes, como si los poderes procesales fueran rebanadas de torta a ser distribuidas de forma limitada entre los sujetos del proceso ${ }^{69}$. En esa necesidad de justicia real, la justificación para la asignación poderes instructores oficiosos al magistrado, una vez el equilibrio se concentra en una palabra importante que las propias Rules inglesas asignan la importancia que corresponde al igual que el art. 8 del CPC brasileño que es la proporcionalidad ${ }^{70}$. La cláusula general del debido proceso legal, por ejemplo, puede resultar en la regla de la obligación de motivación de las decisiones judiciales y en el principio de cooperación. Por lo tanto, reglas, principios y cláusulas generales no pueden ser confundidos entre sí, ya que operan en niveles diversos del fenómeno normativo ${ }^{71}$. En esta nueva visión, el ciudadano se convierte en el nuevo centro metodológico del proceso, y la defensa de sus derechos e intereses pasa a ser el elemento central de la actividad, no solo del magistrado, sino de todos los demás sujetos procesales, puesto que se concientiza recaer sobre todos el deber de dignificación de la justicia, la cual, por otra parte, pasa a ser perseguida sustancialmente y a su debido tiempo ${ }^{72}$.

\footnotetext{
${ }^{64}$ MEDEIROS Y OLIVEIRA (2016), pp. 163-191.

${ }^{65}$ MARINONI Y MITIDIERO (2016), pp. 150-154.

66 ZUFELATO (2019), pp. 45-60; MARINONI Y MITIDIERO (2016), pp. 155-160.

${ }^{67}$ Refiriéndose al perito en derecho e informes en derecho y su influencia para la decisión ya JOLOWICZ (1977), pp. 285-300.

${ }^{68}$ MARINONI Y MITIDIERO (2016), pp. 166-168.

${ }^{69}$ MEDEIROS Y OLIVEIRA (2016), pp. 163-191.

${ }^{70}$ TARUFFO (2006), pp. 451-483.

${ }^{71}$ DIDIER JR. (2010b), pp. 66-67; basta el fundamento del contradictorio más que la cooperación en la línea de ZUFELATO (2019), pp. 153195.

${ }^{72}$ KLEIN (1891), pp. 8-25.
} 
El derecho fundamental a la jurisdicción no puede interpretarse estrictamente como un derecho de acceso a los tribunales para el ejercicio de un derecho de acción o de defensa, ya que su espectro es mucho más amplio, correspondiendo, en verdad, a un derecho de tutela jurisdiccional efectiva ${ }^{73}$. Como se sabe, la jurisdicción se ejerce a través del proceso, que le sirve de instrumento, y que debe obedecer al principio del debido proceso legal. En la actualidad, tal principio conduce el proceso a un formalismo estructurado de forma equitativa y proporcional, orientándose a la concreción de un resultado sustancialmente justo (individual y socialmente) de ahí hablar de un debido proceso equitativo o justo ${ }^{74}$. La propia doctrina brasileña reconoce que los países que adoptaron el protagonismo judicial se presentan, en su mayoría, como de régimen democrático, utilizando como ejemplo el caso de Inglaterra, país de régimen democrático y cuna del modelo adversarial de proceso. Originalmente concedía a las partes exclusividad en la actividad procesal, lo que reformó desde 1998, con la entrada en vigor de la Civil Procedure Rules inglesas, incluso concedió ciertos poderes instructores oficiosos a los magistrados ${ }^{75}$.

Finalmente, el modelo austríaco apoyado en la propia Convención Europea de Derechos Humanos (Art. 6 (1)) sustenta la prohibición de decisiones sorpresas. El artículo 6 no requiere una discusión legal (esto incluye una discusión detallada de las circunstancias legales que el tribunal considera relevantes para su decisión) Sin embargo si el tribunal sorprende a las partes con una visión jurídica sin previo contradictorio, violaría aquel artículo de la Convención. La aplicación se hace extensiva a posibles cambios de jurisprudencia instados por el tribunal que requerirá una previa comunicación a las partes y una oportunidad para comentar y controvertir ello. El ZPO (Código Procesal Civil) austríaco toma en cuenta esto mediante la prohibición de la decisión sorpresa consagrada en la §182a, que también se aplica al tribunal de apelación ${ }^{76}$.

Con la reforma austríaca del 2002 la disposición de la ZPO § 182a introducida estandariza el deber del tribunal de discutir los argumentos fácticos y legales de las partes con ellos y estipula la prohibición de decisiones sorpresivas derivadas del caso. En consecuencia, aparte de las reclamaciones secundarias (intereses, costos, etc.), el tribunal puede basar su decisión solo en los aspectos legales que una parte claramente ha pasado por alto o que se considera insignificante, si los ha discutido previamente con las partes y les ha dado la oportunidad de comentarlos ${ }^{77}$. Por lo tanto, la norma de que las partes no pueden sorprenderse por una opinión jurídica se incluyó expresamente. Sin embargo, sorprendentemente, según la jurisprudencia anterior, era solo una una facultad del tribunal y las partes no tenían oportunidad para debatirlos. En Austria durante décadas, el Tribunal Supremo de Austria ha sostenido sistemáticamente que las partes en un caso no deben sorprenderse por una opinión legal que no han tenido en cuenta y que no han llamado la atención que es propuesta en la audiencia para discusión por el tribunal ${ }^{78}$. Ahora por disposición expresa extiende los deberes de los tribunales, porque una parte también puede pasar por alto o haber considerado aspectos legales insignificantes incluso ya alegados por la contraparte. Si el tribunal de primera instancia los reconoce, debe señalarlo en el contexto de la discusión de los argumentos

\footnotetext{
${ }^{73}$ Así las sentencias coincidentes sobre este punto del Tribunal de Seguridad Social alemán SZ 50/35 = JBI 1978, 262; JBI 1988, 467; SZ 64/173 = SSV-NF 5/134; SSV-NF 6/114.

${ }^{74}$ WALDNER et al. (2000), pp. 25-35.

${ }^{75}$ Comp. BARBOSA (2005), pp. 4-7; para la importancia de la reforma en el Reino Unido ver ANDREWS (2012), pp. 97-109;

${ }^{76}$ RECHBERGER Y SIMOTTA (2017), p. 608; RASSI (2013), p. 767.

77 KREMER Y WITTMANN (2018), pp. 574-576.

${ }^{78}$ Ya sostenido por SPOHR (1969), pp. 15-35. Así lo decidido por la Corte Suprema alemana OGH, sentencia del 7/4/1981, 4 Ob 546/80; OGH, decisión de 16 de febrero de 1984, 6 Ob 8/83; SZ 54/181; SZ 50/35; JBI. 1983, 316; SZ 42/28.
} 
fácticos y legales sino hay un vicio de procedimiento ${ }^{79}$. Si el tribunal no lleva a cabo la llamada "discusión legal ", y no obstante posteriormente emite una decisión basada en consideraciones legales no discutidas, hay una" decisión sorpresa "en el sentido de la ZPO de Austria ${ }^{80}$.

\section{Deber de cooperación judicial, iura novit curia y prohibición de sentencias sorpresivas}

El principio de la cooperación implica el fortalecimiento del deber de lealtad procesal, ya impuesto a las partes por el principio de la buena fe procesal, tienen un deber de esclarecimiento y colaboración con el magistrado para la búsqueda de la verdad contenida en los hechos que dieron origen a la controversia discutida en juicio ${ }^{81}$. En lo que pertenece al magistrado, la incidencia de tal principio en el proceso resulta en la atribución de deberes funcionales de prevención, auxilio, aclaración y consulta tal cual vimos explicitados en el modelo alemán ${ }^{82}$.

El deber de consulta, como se ha señalado repetidamente, representa un punto de interacción entre el principio de cooperación y el principio de contradicción, en la medida que, con el fin de cooperar para la realización de la justicia sustancial del litigio, el magistrado queda encargado de impulsarlo a lo largo del litigio ${ }^{83}$. La imperatividad de la observancia del contradictorio efectivo impone el deber de cooperar al tribunal con las partes para garantizar la debida discusión y evitar decisiones-sorpresa ${ }^{84}$.

Así pues, configuradas por la ausencia de contradictorio previo de las partes en relación con las cuestiones de hecho o de derecho pertinentes a la causa - en los casos en que no se reste autorizado el ejercicio diferido o eventual del mismo-, las decisiones sorpresa se consideran perniciosas a la realización del proceso ${ }^{85}$. La prohibición de las decisiones sorpresa resulta de una dimensión del principio del contradictorio o de un cierre del principio de cooperación ${ }^{86}$.

La prohibición de las decisiones-sorpresas surge en los ordenamientos jurídicos modernos como resultado de la nueva estructuración del proceso, desde que este pasa a exigir una participación activa y cooperada en contradictorio entre los sujetos procesales ${ }^{87}$. Este último comprende el poder de influencia de las partes sobre el conocimiento judicial ${ }^{88}$. Una decisión, por lo tanto, que prescinda del debate trilateral entre los sujetos del proceso en cuanto a cualquiera de sus elementos fundantes no podrá ser considerada legítima, por haber sido pronunciada en sorpresa de las partes ${ }^{89}$.

En definitiva cuando todo ha sido debidamente discutido entre los sujetos del proceso, posibilitando la aclaración de los puntos eventualmente oscuros, dudosos, así como la oportunidad de manifestación de las perspectivas a ser abordadas el juez frente a los hechos constatados, se

\footnotetext{
79 OGH, "sentencia de 25 de mayo de 2005, 7 Ob 83/05i"; OGH, "sentencia v. de 25 de julio de 2014, 5 Ob 117/14p". En ambos fallos se revocó lo decidido en segunda instancia por no comunicar el tribunal a las partes que iba a decidir conforme a una tesis juídica no incorporada por ninguna de las partes. Si bien cabía hacerlo de oficio no dio oportunidad a las partes para discutir el (nuevo) fundamento jurídico que consideró aplicable.

${ }^{80}$ RASSI (2015); FUCIK (2015); Según decisión del OGH, sentencia de 2 de mayo de 1984, 1 Ob 544/84; OGH, sentencia de 15 de diciembre 1988, 6 Ob 739/88.

${ }^{81}$ ALFARO (2014), pp. 20-45

82 GRASO (1966), p. 587.

83 FERRAND (2007), pp. 895-900.

${ }^{84}$ GRASSI (2015), pp. 123-136.

${ }^{85}$ FRITSCHE (2016), pp. 41-43; DOMIT (2016), pp. 15-35.

${ }^{86}$ REIMER (2015), pp. 366-369.

${ }^{87}$ BARTEL (2014), pp. 321-346.

${ }^{88}$ HENKE (2005), p. 1028; en este sentido se pronunció el Supremo Tribunal en lo Administrativo alemán VGH München, sentencia del 23.10.2017-20 ZB 16.30113.

${ }^{89}$ CHIARLONI (2008), p. 144; FABIANI (2009), p. 264.
} 
permite la formación de una unión más bien sedimentada y cercana a la realidad sustancialmente perseguida, haciéndola menos sujeta a recursos ${ }^{90}$. A partir del momento en que, aparte, se posibilita participar en el proceso en la claridad de los materiales que serán considerados para dictar la sentencia, disminuye el afán impugnativo contra la misma, trayendo más celeridad y justicia al proceso como instrumento para la entrega de la tutela judicial ${ }^{91}$.

En el proceso civil francés, la primera parte del dispositivo es inspirado en el tramo inicial del art. 16 del Código de Proceso Civile, que impone al magistrado el deber no solo asegurar la observancia del contradictorio, sino también de observarlo él mismo. Se registra, además, que el contradictorio es visto por la doctrina francesa como un instrumento importante para la persecución de uno de sus motes principales, que es el mantenimiento del equilibrio en la relación entre partes y el órgano jurisdiccional ${ }^{92}$. Por eso mismo, además, los poderes de dirección del magistrado deberán siempre estar amoldados de modo que permitan una amplia discusión trilateral del objeto de la causa. Innova en relación con el principio dispositivo, sin embargo, al introducir a través de un término indeterminado, cuyo contenido debe ser cumplimentado por el magistrado-, mantiene una reserva a la obligatoriedad del contradictorio previo de las partes ${ }^{93}$. Abre, con ello, espacio para cuestionar acerca de la amplitud de discrecionalidad que se daría al magistrado para decidir las hipótesis en que estaría autorizado a dispensar el contradictorio ${ }^{94}$. Por ello lo que debe permitirse a las partes cooperar para la búsqueda de la verdad no solo a través de la exposición de los hechos, así como a través de la argumentación jurídica ${ }^{95}$. Incluso porque, el hecho y el derecho están umbilicalmente conectados, interpelándose recíprocamente, en el proceso, de modo que su separación no es más que una artificialidad ${ }^{96}$. Lo dicho para los tribunales estatales también la doctrina alemana y austríaca lo ha extendido a los arbitrales ${ }^{97}$.

\section{Conclusiones}

Los nuevos paradigmas del proceso civil imponen una reformulación cooperativa de la visión del lura Novit Curia. Ello no significa que el juez sustituye en esta visión a las partes quienes pueden disponer sobre el objeto del proceso. Sí conlleva que el juez no puede decidir un caso en base a una hipótesis jurídica, aunque no haya sido propuesta por las partes, sin que previamente sea discutida con ellas dentro del marco del contradictorio ${ }^{98}$. Así, el axioma jurídico iura novit curia, que, en su origen, era responsable de traspasar la idea que, al magistrado, se impondría el deber de conocer del derecho aplicable o, de lo contrario, investigarlo de oficio. Se trata de una visión más relativizada que permite que las partes puedan cooperar con el órgano jurisdiccional en la búsqueda de la

\footnotetext{
90 MARINONI Y MITIDIERO (2016), p. 217.

91 WALDNER et al. (2000), pp. 5-20. Disposiciones contenidas en el §278 antes de la reforma del 2002 que se reformulan en el §139. En la antigua ubicación de la norma además del texto citado ver HELBIG (1979), pp. 15-35.

92 GUINCHARD (1999), p. 7.

${ }^{93}$ SPOHNHEIMER (2010), pp. 271-275;

${ }^{94}$ FERRAND (2000), pp. 345-369.

${ }^{95}$ Sobre el derecho de acceso a la justicia y la necesidad de que el juez aplique la ley que corresponde para el caso escuchando a las partes ver CHIUARIU (2019), pp. 593-604.

${ }^{96}$ Sostuvo el Supremo Tribunal Federal alemán :" En principio, un Tribunal de Apelaciones no tiene que indicar que desea apartarse de la opinión del Tribunal de Primera Instancia si la sentencia del tribunal de primera instancia en la que se basa la sentencia recurrida es un tema central para su revisión por el Tribunal de Apelación y, por lo tanto, la parte interesada está exenta de la decisión del Tribunal de Primera Instancia" BGH, decisión de 19 de agosto de 2010 - VII ZR 113/09 (NJW 2010, 3089).

${ }_{97}$ SCHLOSSER (2016), en relación a la prohibición de las decisiones sorpresas por parte de un tribunal arbitral.

${ }^{98}$ ALFARO (2014), pp. 15-25.
} 
solución más adecuada. Entre el juez y las partes existe una comunidad de intereses en la resolución del litigio antes que una confrontación ${ }^{99}$.

Lo que se pretende, en verdad, es amoldar tal axioma a la nueva estructuración del proceso civil contemporáneo ${ }^{100}$. Y así, puntualizar que, aunque cumpla al magistrado el deber de decir el Derecho aplicable al caso concreto - al final, a él compete el ejercicio del iuris dictio (de jurisdicción), teniendo siempre la palabra final-, deberá mostrarse siempre abierto a las contribuciones que puedan derivarse de las actividades realizadas por las partes. Incluso porque, en un proceso cooperativo, todos los sujetos procesales, cada uno en el ejercicio de sus propias prerrogativas y funciones, tienen el deber de contribuir a la aparición de la verdad, esencial para una justa composición del litigio ${ }^{101}$.

\section{BIBLIOGRAFÍA CITADA}

AGUIRREZABAL GRÜNSTEIN, MAITE Y PÉREZ RAGONE, ÁlVARO (2018): "Dirección compartida del proceso civil", en: Revista de Derecho Privado de la UNAM (Año V, № 14), pp. 57-83.

ALFARO VALVERDE, LUIS (2014): El principio de audiencia. Barcelona. Evolución e influencia en el proceso civil (Barcelona, Bosch).

ANDREWS, NEIL (2012): "Fresh Start: The Four Pillars of Civil Justice", en: Shetreet, S. y Forsyth, C. (Coords.), The Culture of Judicial Independence (Leiden-Boston, Nijhoff), pp. 97-109.

BALLON, OSKAR (1995): "Die Beachtung des rechtlichen Gehörs iSd Art 6 EMRK durch die Rechtsmittelgerichte", en: Juristische Blätter, p. 623.

BARBOSA MOREIRA, JOSÉ CARLOS (2005): "O neoprivativismo no processo civil", en: Temas de Direito Processual: Nona Serie, San Pablo, Revista dos Tribunais, pp. 4-25.

BARTEL, LOUISA (2014): Das Verbot der Rekonstruktion der Hauptverhandlung: Versuch einer Legitimation (Tübingen Mohr, Siebeck).

BAUR, FRITZ (1968): Parteirechte und Richterpflichten im modernen Zivilprozess-Wandlungen und Erfahrungen, en: FS Kralik, Viena, Manz, pp. 75-82.

(1980): "Parteirechte und Richterpflichten im modernen Zivilprozess-Wandlungen und Erfahrungen”, en: FS Kralik, Wien, Manz (1968), pp. 76 y ss.

BOURSIE, MARIE-EMMA (2003): Le principe de loyauté in droit processuel (Paris, Dalloz).

BÜNNIGMANN, KATHRIN (2013): Die "Esra"-Entscheidung als Ausgleich zwischen Persönlichkeitsschutz und Kunstfreiheit (Tübingen, Mohr Siebeck).

\footnotetext{
${ }^{99}$ CAVALLINI (2017), pp. 1-8.

${ }^{100}$ MITIDIERO (2011), pp. 55-68.

${ }^{101}$ FERRERI (2012), pp. 48-50.
} 
CABRAL, ANTONIO (2005): “Il principio del contraddittorio como diritto d'influenza e dovere di dibattito", en: Rivista di Diritto Processuale ( $\mathrm{N}^{\circ} 2$ ), pp. 450-468.

(2010): "Contraditório (Princípio do)", en: Lobo Torres, Ricardo; Takemi Kataoka, Eduardo; Galdino, Flávio (Orgs.), Dicionário de Princípios Jurídicos (Rio de Janeiro, Campus Jurídico), p. 201.

CADIET, LOIC (2010): "Avenir des catégories, catégories del'avenir: perspectives", en: Common Law, Civil Law and the Future of Categories (Markham, LexisNexis), pp. 635-655.

CADIET, LOIC; NORMAND, JACQUES Y AMRANI MEKKI, SORAYA (2010): Théorie général du procés (Paris, PUF Ed.).

CAPONI, REMO (2001): "Brevi note sul contraddittorio in condizioni di parità nel processo civile", en: Civinini, M. G. y Verardi, C. M. (Coords.), II nuovo articolo della Costituzione e il giusto proceso civile. Atti del Convegno dell'Elba (Milano, FrancoAngeli Editore), p. 282.

CARNEIRO, PAULO (2015): "O contraditório participativo vedação às decisões surpresas", en: Wambier, Teresa Arruda Alvim et al. (Orgs.), Breves comentários ao novo código de processo civil (São Paulo, Revista dos Tribunais) pp. 76-79.

CAVAlLINI, CESARE (2017): "Why is the lura Novit Curia Principle not Applied Yet in English Law?", en: Global Jurist (Vol. 17, Issue 3), pp. 1-8.

CHIARLONI, SERGIO (2008): "Giusto processo, garanzie processuali, giustizia della decisione", en: Riv. trim. dir. proc. civ., p. 129-152.

(1987): "Questioni rilevabili d' ufficio, diritto di difesa e 'formalismo delle garanzie", en: Rivista Trimestrale di Diritto e Procedura Civile ( $N^{\circ} 1$ ), pp. 575-580.

CHIUARIU, TUDOR-ALEXANDRU (2019): "The Overthrow of the general Principle of Law iura novit Curia or the Judge's Desire not to Apply the Law. The Restriction of the Right of Access to Court in the Contentious Administrative Subject to a Time Limit", en: AAVV, Romanian Law, Tradition and European Vocation, 6ạ edición (Bucarest, Ed. Hamangiu), pp. 593-604.

COMOGLIO, LUIGI PAOLO (1989): “Contraddittorio", en: Comoglio, Luigi Paolo; Ferri, Corrado; Taruffo, Michelle (Coords.), Digesto delle discipline privatistiche, Sezione civile, 4a edición (Torino, UTET), volumen IV, p. 26.

DIDIER JR., FREDIE (2010a): Fundamentos do Princípio da cooperação no direito processual civil português (Coimbra, Wolters Kluwer Portugal Ed.).

(2010b): Fundamentos del principio de cooperación procesal en el derecho procesal civil portugués (Lima, Communitas). 
DINAMARCO, CANDIDO RANGEL (2008): "A instrumentalidade do proceso", en: San Pablo Revista dos Tribunais Ed., pp. 20-35.

DOMIT, OTÁVIO (2016): "Iura Novit Curia e causa de pedir", en: San Pablo Revista dos Tribunais Ed., pp. 15-30.

EZQUIAGA GANUZAS, FRANCISCO JAVIER (2000): Iura novit curia y aplicación judicial del derecho (Valladolid, Lex Nova).

FABIANI, ERNESTO (2009): “Contraddittorio e questioni rilevabili d'ufficio", en: Foro it. (NNo V), p. 264.

FERRAND, FRÉDÉRIQUE (2000): “Le principe contradictoire et l'expertise en droit comparé européen", en: Revue internationale de droit comparé (Vol. 52 N² 2, abril-junio), pp. 345-369.

(2007): Droit Processuel-Droit Commum et Droit Comparé du Procès équitable, 4ạ edición (Paris, Dalloz Ed.).

FERRERI, SILVIA (2012): "Complexity of Transnational Sources", en: Brown, Karen; Snyder, David V., General Reports of the XVIIIth Congress of the International Academy of Comparative Law (Dordrecht/London/Heidelberg, Springer), pp. 48-50.

FREITAS, JOSÉ (2013): Introdução ao Processo Civil: Conceito e princípios gerais à luz do novo código, 3a edición (Coimbra, Coimbra Editora).

FRITSCHE, JÖRN (2016): Münchener Kommentar ZPO (Múnich, Beck), tomo 1.

FRITZ, HELBIG (1979): Das Verbot von Überraschungsentscheidungen nach \$278 III (Freiburg, Tesis Doctoral).

FUCIK, ROBERT (2015): "Zivilprozessordnung", en: Rechberger (Coord.), Zivilprozessordnung (Viena, Ed. Österreich), § 182a ZPO.

GOMILLE, CHRISTIAN (2016): Informationsproblem und Wahrheitspflicht (Tübingen, Mohr Siebeck).

GRASSI, LÚCIO (2015): “Audiência de saneamento e organização no Código de Processo Civil cooperativo brasileiro de 2015", en: Revista Brasileira de Direito Processual: RBDPro, Belo Horizonte (Vol. 23, № 91, jul./set.), pp. 123-136.

GRASSO, EDUARDO (1966): "La collaborazione nel processo civile", en: Rivista di Diritto Processuale, p. 587.

GREGER, REINHARD (2000a): "Kooperation als Prozessmaxime", en: Gottwald, Schwab, Prútting (Coords.), Dogmatische Grundfragen des Zivilprozesses im geeinten Europa (Bielefeld, Gieseking Ed.), pp. 73-84.

(2000b): “Justizreform? Ja, aber...", en: Jurische Zeitung, pp. 842-853. 
GUASTINI, RICCARDO (2014): L'interpretazione dei documenti normativi (Milano, Giuffrè Ed.).

GUINCHARD, SERGE (1999): "Le contradictoire au regard de la Convention européenne des Droits de I'Homme et du droit constitutionnel", en: Experts-C.E.J. (sept.), p. 7.

HANSENS, HEINZ (2002): “Die ZPO-Reform”, en: Antwalt Blätter, pp. 125-127.

HELBIG, FRITZ (1979): Das Verbot von Überraschungsentscheidungen nach § 278 III ZPO (Freiburg, Dissertation, Tesis Doctoral).

HENKE, HORST-EBERHARD (2005): "Die aufklärende Prozessleitung des Zivilrichters", en: Juristische Zeitung, p. 1028.

HUNTER, IVÁN (2010): "Iura novit curia en la jurisprudencia civil", en: Revista de Derecho de la Universidad Austral de Chile (№ II), pp. 201-216.

(2013): "Iura novit curia y el Proyecto de Código Procesal Civil: ¿Para qué sirve definir los poderes del juez en la aplicación del Derecho?", en: Revista de Derecho de la Pontificia Universidad Católica de Valparaíso (№ XL, 1은 Semestre), pp. 601-640.

JOLOWICZ, JOHN ANTHONY (1977): "L'expert, le témoin et le juge dans le procès civil en droits français et anglais", en: Revue internationale de droit comparé (№ 29-2), pp. 285-300.

KAUFMANN-KOHLER, GABRIELLE (2004): “lura novit arbiter: Est-ce bien raisonnable?", en: Héritier Lachat, Hirsch (Dir.), De lege ferenda: Réflexions sur le droit désirable en l'honneur du Professeur Alain Hirsch (Genève, Ed. Slatkine), p. 71.

KETTEMBEIL, KURT (1978): Juristische Überraschungsentscheidungen als Problem von Logik und Sturkturen im Recht (Frankfurt, Peter Lang).

KLEIN, FRANZ (1891): Pro futuro. Probleme der Zivilprozessreform in Österreich (Leipzig, Franz Deuticke).

Manz).

(1927): "Zeit- und Geistesströmungen", en: Reden, Vorträge, Aufsätze, Briefe (Viena, KOCH, MELANIE (2003): Die richterliche Prozessförderungspflicht nach dem ZPO-Reformgesetz (Hamburg, Kovac).

KOCH, RAPHAEL (2013): Mitwirkungsverantwortung im Zivilprozess (Tübingen, Mohr Siebeck).

KOCHEM, RONALDO (2016): "Introdução as raizes historicas do principio da cooperação (Kooperationsmaxime)", en: Revista de Processo (№ 251), pp. 75-111. 
KREMER, RALF Y WITTMANN, CHRISTIAN (2018): Vertragsärztliche Zulassungsverfahren (Heidelberg, Müller Ed.).

KUGLER, KLAUS (2002): Die Kooperationsmaxime-Richtermacht und Parteienherrschaft im Zivilprozess der gemeinsame Weg zum richtigen Prozessergebnis (Linz, Trauner Ed.).

LÖCHER, JENS (2005): Die Anhörung im Sozialverwaltungsverfahren (Würzburg, Tesis Doctoral).

MARINONI, LUIZ GUILHERME; ARENHART, SÉRGIO Y MITIDIERO, DANIEL (2015): Novo Curso de Processo Civil: Teoria do Processo Civil (São Paulo, Editora Revista dos Tribunais), volumen 1.

MARINONI, LUIZ GUILHERME Y MITIDIERO, DANIEL (2016): Comentários ao Código de Processo Civil (San Pablo, Thomson Reuter-Revista dos Tribunais), tomos I y XV.

MEDEIROS NETO, ELIAS Y OLIVEIRA MACHADO, PEDRO ANTONIO (2016): "Princípio da cooperação no processo civil”, en: Revista Thesis Juris (Vol. 5, № 1), pp. 163-191.

MEIER, ISAAK (2014): “Die unbeziffierte Forderungsklae und Waffengleicheit der Parteien", en: X Ankara, Tirkiye Adalet Akamisi (№ 69), pp. 35-67.

MEROI, ANDREA (2007): "Iura Novit Curia y decisión imparcial”, en: lus et Praxis (Año 13, № 2), pp. 379390.

MITIDIERO, DANIEL (2004): "Processo e Cultura: praxismo, processualismo e formalismo em direito processual civil”, en: Revista Cadernos do Programa de Pós-Graduação em Direito PPGDir./UFRGS, pp. 487-488.

(2009): Colaboração no processo civil: pressupostos sociais, lógicos e éticos (San Pablo, Revista dos Tribunais).

(2011): “Colaboração no processo civil como prêt-à-porter? um convite ao diálogo para Lenio Streck", en: Revista de Processo, São Paulo (Vol. 194, abr.), pp. 55-68.

OLIVEIRA, CARLOS (2006): "O formalismo-valorativo no confronto com o formalismo excessivo", en: Revista da Faculdade de Direito da UFRGS- (№ 26), p. 66.

(2003): "A garantia do contraditório", en: Oliveira, Carlos Alberto Álvaro, Do formalismo no processo civil, 2a edición (San Pablo, Saraiva Ed.), pp. 62-67.

ORMAZÁBAL SÁNCHEZ, GUILLERMO (2007): Iura novit curia. La vinculación del juez a la calificación jurídica de la demanda (Madrid, Marcial Pons).

PENNEC, LAURENT (2010): L'adage jura novit curia: émergence et approche dans le procès civil contemporain, Etude de droit comparé (Toulon, Tesis doctoral). 
PICARDI, NICOLA (2003a): “"Audiatur et altera pars». Le matrici storico-culturali del contraddittorio", en: Riv. Trimest. Dir. e Proc. Civ. (№ 1), pp. 7-22.

(2003b): "La funzione del giudice nell'interpretazione e nell' applicazione del diritto", en: Giustizia Civile, p. 53.

PROTO PISANI, ANDREA (2010): "Appunti su queslioni rilevavile d'ufficio e principio de contraddittorio", en: Foro, il. (V, c.), p. 301.

PRÜTTING, HANNS (1980): “Die Grundlage des Zivilprozesses im Wandel der Gesetzgebung”, en: Neue Juristische Wochenschrift, p. 361.

(2016a): ZPO-Kommentar (Colonia, Otto Schmidt Ed.).

(2016b): Münchener Kommentar ZPO (Múnich, Beck), tomo 1.

PUTMAN, EMMANUEL Y JUBAULT, CHRISTIAN (2010): "Recension", en: Revue trimestrielle de droit civil (№ 1), pp. 188-202.

RASSI, JÜRGEN (2013): "Die richterliche Anleitungspflicht und das Verbot von Überraschungsentscheidungen in der österreichischen Rechtsprechung - Entwicklungen seit der Zivilverfahrensnovelle 2002", en: Schumacher/Zimmermann (Coord.), Festschrift für Gert Delle Karth (Viena, Sramek), p. 767.

(2015): “Comentario", en: Fasching/Konecny (Coord.), Zivilprozeßgesetze II/33 (Viena, Manz) §§ 182, 182a ZPO, pp. 49-55.

RECHBERGER, WALTER Y SIMOTTA, DAPHNE (2017): Grundriss des österreichischen Zivilprozessrechts: Erkenntnisverfahren, 9a edición (Viena, Manz).

REIMER, PHILIPP (2015): Verfahrenstheorie (Tübingen, Mohr Siebeck).

REISCHL, KLAUS (2003): “Der Umfang der richterlichen Instruktionstätigkeit - ein Beitrag zu § 139 Abs. 1 ZPO”, en: Zeitschrift für Zivilprozess ( $N^{\circ} 81$ ), pp. 81-102.

RENSEN, HARTMUT (2002): Die richterliche Hinweispflicht (Bielefeld, Gieseking Ed.).

RIMMELSPACHER, BRUNO (1996): Zur Prüfung von Amts wegen im Zivilprozeß (Universidad Göttingen, Göttingen).

SCHAEFER, THOMAS (2002): "Was ist neu an der neuen Hinweispflicht?", en: Neue Juristische Wochenschrift, p. 849.

SCHARWITZL, ALEXANDER (2013): Die richterliche Anleitungspflicht im Spannungsfeld zwischen Wahrheitsfindung und Parteilichkeit unter besonderer Berück- sichtigung des, Überraschungsverbotes, Tesis doctoral (Viena, U. Viena). 
SCHELLHAMMER, KURT (2001): "Zivilprozessreform und erste Instanz", en: Monatsschrift für Deutsches Recht, p. 1081.

SCHLOSSER, PETER (2016): “Kommentar zur Zivilprozessordnung”, en: Stein, Friedrich y Jonas, Martin (Coords.), Kommentar zur Zivilprozessordnung, 23a edición (Tübingen, Mohr Siebeck), § 1051, № 4.

SCHNEIDER, EGON (2002): ZPO-Reform (Colonia, Zap-Verlag für die Rechts- U. Anwaltspraxis Ed.).

SCHÖPFLIN, MARTIN (1992): Die Beweiserhebung von Amts wegen im Zivilprozess (Frankfurt aM., Peter Lang).

SENTís MELENDO, SANTIAGO (1957): El juez y el derecho (Buenos Aires, Ediciones Jurídicas EuropaAmérica).

SMID, STEFAN (2012): "Zivilprozessordnung", en: Wieczorek, Bernhard y Schütze, Rolf (Dirs.), Zivilprozessordnung (Berlin, De Gruyter), §139.

SPOHNHEIMER, FRANK (2010): Gestaltungsfreiheit bei antezipiertem Legalanerkenntnis des Schiedsspruchs (Tübingen, Mohr Siebeck).

SPOHR, TILMAN (1969): Die richterliche Aufklärungspflicht (§139) im Zivilprozess, Tesis Doctoral (Göttingen, Universidad Göttingen).

SPRUNG, RAINER Y KÖNIG, BERNHARD (1976): "lura novit curia und rechtliches Gehör", en: Juristische Blätter, p. 1.

STICKELBROCK, BARBARA (2002): Inhalt und Grenzen richterlichen Ermessens im Zivilprozeß (Köln, Otto Schmidt Ed.).

STÜRNER, ROLF (1976): Die Aufklärungspflicht der Parteien des Zivilprozesses (Tübingen, Mohr Siebeck). (1982): Die richterliche Aufklärung im Zivilprozeß (Tübingen, Mohr Siebeck).

(1985): "Parteipflichten bei der Sachaufklärung im Zivilprozess", en: Zeitschrift für Zivilprozess (№ 98), pp. 237-255.

TARUFFO, MICHELE (2006): "Poteri probatori delle parti e del giudice in europa", en: Rivista trimestrale di diritto e procedura civile (Milano, № 2), pp. 451-483.

TARZIA, GIUSEPPE (1981): “Le principe du contradictoire dans la procédure civile italienne”, en: Revue Internationale de Droit Comparé, p. 789. 
THEODORO JÚNIOR, HUMBERTO Y NUNES, DIERLE (2009): “Uma dimensão que urge reconhecer ao contraditório no direito brasileiro: sua aplicação como garantia de influência, de não surpresa e de aproveitamento da atividade procesual”, en: Revista de Processo (№ 168), pp. 107-141.

THEODORO JÚNIOR, HUMBERTO (2011): "Juiz e partes dentro de um processo fundado no principio de cooperação", en: Revista Dialética de Direito Processual (№ 102), p. 64.

TORRES GALINDO, MAIRA (2014): Princípio da cooperação: dever de consulta e a proibição das decisõessurpresa, Tesis (Universidad de Coimbra, Coimbra).

VENTSCH, VERENA (2005): Die materielle Prozessleitung nach der Reform der Zivilprozessordnung (Hamburg, Kovac).

WALDNER, WOLFRAM; PRÜTTING, HANNS Y WETH, STEPHAN (2000): Der Anspruch auf rechtliches Gehör, 2a edición (Colonia, Otto Schmidt Ed.).

WAMBIER, TERESA (2009): "Influência do contraditório na convicção do juiz: fundamentação de sentença e de acórdão", en: Revista de Processo (№ 168), pp. 53-60.

WASSERMANN, RUDOLF (1978): Der soziale Zivilprozess (Darmstadt, Luchterhand Ed.).

WIEGAND, WOLFGANG (2005): "Iura novit curia vs. ne ultra petita. Die Anfechtbarkeit von Schiedsgerichtsurteilen im Lichte der jüngsten Rechtsprechung des Bundesgerichts", en: Jametti Greiner/Berger/Güngerich (Coord.), Festschrift für Franz Kellerhals (Berna, Stämfli Ed.), p. 127.

ZUFELATO, CAMILO (2019): Contraditório e vedação às decisões-surpresa no processo civil brasileiro (Belo Horizonte, Ed. D'Plácido).

\title{
JURISPRUDENCIA CITADA
}

\author{
ALEMANIA \\ BVERFG, en NJW, 1976, 1391. \\ SZ 50/35, en JBI 1978, 262. \\ BGH (1984), p. 310. \\ BVERFGE (1984), p. 190. \\ BVERFGE 10, p. 182. \\ BVERFGE 15, 218. \\ BVERFGE 51, p. 192; 75, p. 190.
}


BGH, en MDR, 2001, 104.

BGH, decisión del 19.8.2010 - VII ZR 113/09 (NJW 2010, 3089).

BGH 29.04.2014 - VI ZR 530/12 (consultado el 4/2/2019).

VGH MÜNCHEN, sentencia del 23.10.2017 - 20 ZB 16.30113.

SZ 64/173.

SSV-NF 5/134.

SSV-NF 6/114.

SZ 54/181.

SZ 50/35.

SZ 42/28.

\section{AUSTRIA}

OGH, sentencia del 7/4/1981, 4 Ob 546/80.

OGH, Entscheidung 16/2/1984, 6 Ob 8/83.

OGH, sentencia del 2/5/1984, 1 Ob 544/84.

OGH, sentencia del 15/12/1988, 6 Ob 739/88.

OGH, sentencia del 25. mayo 2005,7 Ob 83/05i.

OGH, sentencia v. 25. julio 2014, 5 Ob 117/14p.

\section{NORMAS JURÍDICAS CITADAS}

\section{ALEMANIA}

GESETZ ZUR REFORM DES ZIVILPROZESSES VOM, BGBI I, Nr. 40, S. 1887, 27 de junio de 2001.

INGLATERRA

CIVIL PROCEDURE RULES. United Kington No. 3132 (L. 17), 1998. 


\section{PORTUGAL}

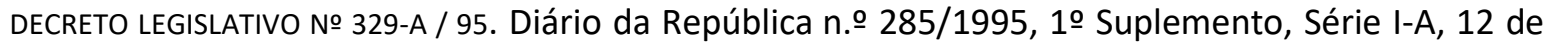
diciembre de 1995.

DECRETO-LEI N.o 180/96, Novo Codigo de Processo Civil. Diário da República n.o 223/1996, Série I-A, 25 de septiembre de 1996.

\section{BRASIL}

LEI N. 13.105, Codigo de Processo Civil CPC. Diário Oficial da União - Seção 1 - 17/3/2015, 16 de março de 2015.

CONVENCIÓN EUROPEA DE DERECHOS HUMANOS. BOE-A-1979-2401. 